\title{
Beneficial effect of kidney transplantation from a deceased donor on severe chronic refractory intradialytic hypotension - a case report
}

Ewa Ignacak', Dominik Cieniawski ${ }^{1 *}$, Alina Bętkowska-Prokop ${ }^{1}$, Czesław Osuch², Marek Kuźniewski ${ }^{1}$ and Władysław Sułowicz'

\begin{abstract}
Background: Chronic refractory hypotension (IDH, intradialytic hypotension) is a rare but serious problem encountered in patients on hemodialysis. Patients with chronic hypotension are often disqualified by transplant teams from renal transplantation. This is due to the possibility of an enormous risk of ischemic complications.

Case presentation: We describe a 44-year old female patient with severe refractory hypotension (mean BP 60/ $30 \mathrm{mmHg}$, the lowest $48 / 28 \mathrm{mmHg}$ ), which appeared after bilateral laparoscopic nephrectomy of the infected kidneys. The kidney transplantation from a deceased donor, with infusion of the two pressor amines (dopamine, dobutamine) was performed without technical complications and the blood pressure measurements were 100-120/70-80 mmHg. The immunosuppression regimen was tacrolimus (TAC) + mycophenolate mophetil (MMF) and steroids (GS). Pressor amines were discontinued on the 18th day after the transplantation. Because of delayed graft function, 4 hemodialysis treatments were performed. The patient was discharged from the hospital on the 22nd day with good function of the transplanted kidney (the concentration of serum creatinine $117 \mu \mathrm{mol} / \mathrm{l})$. During one-year follow-up, the patient has been remaining stable with a very good graft function (serum creatinine $84 \mu \mathrm{mol} / \mathrm{l})$ and normal blood pressure $(115 / 70 \mathrm{mmHg})$.
\end{abstract}

Conclusions: Proper preparation and adequate perioperative treatment allowed for safely performing kidney transplantation in the patient with severe IDH.

Keywords: Intradialytic hypotension, Kidney transplantation, Hemodialysis, Case report

\section{Background}

Dialysis hypotension (IDH, intradialytic hypotension) is a frequent complication in patients undergoing chronic hemodialysis (HD). It is estimated that it affects approximately $10-70 \%$ of patients. Significant differences in the incidence are associated with various definitions of this disease. KDOQI (The National Kidney Foundation's Kidney Disease Outcomes Quality Initiative) defines IDH as a decrease in systolic blood pressure $>20 \mathrm{mmHg}$ or a decrease in mean arterial blood pressure (BP) of $>10 \mathrm{mmHg}$

\footnotetext{
* Correspondence: dominik.cieniawski@gmail.com

${ }^{1}$ Department of Nephrology, Jagiellonian University, ul. Kopernika 15C,

31-501, Krakow, Poland

Full list of author information is available at the end of the article
}

with associated clinical symptoms (abdominal discomfort, nausea, vomiting, fainting, dizziness, muscle cramps, etc.). According to the KDOQI definition, IDH applies to approximately $20-30 \%$ of dialysis session [1].

IDH may occur as a form of acute (episodic), recurrent (for a minimum of $50 \%$ of the dialysis session) or rarely chronic dialysis hypotension, which is associated with the occurrence of $\mathrm{BP}<100 \mathrm{mmHg}$ between HD sessions in $5-10 \%$ of patients. IDH is more common in elderly patients with cardiovascular disease, on long-term dialysis, in patients with diabetes, low levels of albumin, a high body mass index (BMI) in women, as well as in patients with low blood pressure before dialysis. The clinical consequences of IDH include primarily a deterioration in the 
quality of life and increased mortality due to cardiovascular complications. The effects of IDH are also associated with a lack of obtaining adequate dialysis, which is associated with the shortening of the dialysis session. The problems involve a vascular accesses - frequent clotting of arteriovenous fistulas $[2,3]$.

The occurrence of IDH is related primarily to the lack of an adequate volume of circulating blood during the dialysis session, which on the one hand results from insufficient refilling plasma, and the other - an impaired hemodynamic response from the myocardium and blood vessels.

Factors affecting the presence of IDH are dependent on the patient: being on antihypertensive medications, the presence of cardiovascular diseases, a considerable weight gain between dialyses, as well as on the manner of HD application (the concentration of sodium, calcium, the osmolarity of the dialyzate, the temperature of the dialysis liquid and the type of buffer used in dialysis), and on additional factors, such as anemia, hypoxia or intercurrent infections.

To date, the pathophysiology of IDH has not been completely understood. On the one hand, it is suggested that a reduced response of the cardiovascular system to vasopressor agents is associated with the occurrence of a reduced response to stimuli from the adrenergic receptors there are indeed elevated levels of norepinephrine, but with a reduced density of alpha 2 adrenergic receptors. In addition, there is a reduced response of alpha1 adrenergic receptors. Long-term dialysis treatment is also associated with an impaired baroreceptor function. Also reduced density and a response from the beta 1 and beta 2 adrenergic receptors have a clinical value. Another factor associated with the occurrence of IDH is an increased production of vasodilators (adrenomedullins and nitric oxide) as a result of an increased production of proinflammatory cytokines. Repeated episodes of organ hypoperfusion, the effect of $\mathrm{IDH}$, are associated on the one hand with hypertrophy and myocardial fibrosis, and on the other - with an increase in the level of endotoxins, which in turn leads to an increased production of proinflammatory cytokines, oxidative stress and dysfunction of endothelial cells [2, 4]. Another cause of IDH may be bilateral nephrectomy leading to removal of sympathetic stimulus from native kidneys [5].

The occurrence of chronic IDH usually leads to disqualification of a patients from the kidney transplantation procedure. To date, there are few reports in the literature of a successful kidney transplantation with an improved BP control in patients with chronic IDH.

\section{Case presentation}

A 44-year-old female patient with severe intradialytic hypotension, (the mean BP were $60 / 30 \mathrm{mmHg}$, the lowest BP $48 / 28 \mathrm{mmHg}$ ) was qualified for renal transplantation by a team from the Department of Nephrology, University Hospital after an in-depth diagnostic management.

The cause of the patient's end-stage renal failure was rapidly progressive glomerulonephritis with anti-GBM treated in the past by plasmapheresis and Solu-Medrol pulses. In addition, since the age of 20 years, she had bilateral nephrolithiasis with recurrent urinary tract infections and hypertension. The patient was on hemodialysis for three years. One year after the commencement of dialysis, the patient underwent bilateral laparoscopic nephrectomy due to bilateral nephrolithiasis and recurrent urinary tract infections - which are an obstacle in qualifying patient for renal transplantation. Since that time, the patient has been severely hypotensive. She denied fainting, reported a significant weakness. In the course of hypotension, ischemic neuropathy with loss of vision in the right eye occurred. In addition, eye pain worsened during dialysis. Collaboration with the patient while renal replacement therapy was carried out was good, and her weight gain between dialysis sessions did not exceed $2000 \mathrm{ml}$. HD sessions were carried out in accordance with the standards for the IDH (the lowered temperature of the dialysis fluid, profiled sodium concentration, short-term infusion of colloids with declined $\mathrm{BP})$. Additionally, the adrenal CT (computed tomography) scan was normal, as well as cortisol and ACTH (adrenocorticotropic hormone) levels. Histological examination of the rectal mucosa sample excluded amyloidosis. The results of cardiac studies (echocardiogram and electrocardiography) were also normal. The orthostatic stress test and Ewing's battery tests showed no abnormalities of the autonomic nervous system, the heart rate variability was normal during the all the tests. Treatment with mineralocorticoids and midodrin did not result in the improvement of BP, but after the dopamine infusion, her blood pressure increased to satisfactory values $(120 / 60 \mathrm{mmHg})$. The results of most relevant laboratory and diagnostic tests performed in patient are showed in Table 1. The patient was referred for renal transplantation and placed on the waiting list. The waiting time for kidney transplantation was 6 months.

The kidney for transplantation was harvested from a deceased donor (33 years old male with overweight, after intracranial injury, without arterial hypertension and other diseases). The number of non-conforming HLA 2 $\mathrm{A}, 1 \mathrm{~B}$ and $1 \mathrm{DR}, \mathrm{PRA}$ max and the last was 0 . The total time of ischemia was $22 \mathrm{~h}$, and warm ischemia - $50 \mathrm{~min}$. The patient used the following immunosuppression regimen: TAC + MMF + GS. Immediately prior to the transplantation procedure, her BP was $60 / 40 \mathrm{mmHg}$. Before the surgery, dopamine infusion at a dose of $5.3-7.4 \mu \mathrm{g} / \mathrm{kg} / \mathrm{min}$ resulted in an increase of BP to $100-120 \mathrm{mmHg}$. The kidney transplantation procedure was performed without complications. In the second day after surgery, the patient was transferred to the Department of Nephrology. Due to the low value of $\mathrm{BP}<100 \mathrm{mmHg}$, dopamine infusion and 
Table 1 Results of most relevant laboratory and diagnostic tests

\begin{tabular}{|c|c|c|}
\hline $\begin{array}{l}\text { Type and name } \\
\text { of diagnostic test }\end{array}$ & Result/Nalue & $\begin{array}{l}\text { Normal } \\
\text { laboratory } \\
\text { range }\end{array}$ \\
\hline Thyroid stimulating hormone & 1.960 & $0.27-4.2$ \\
\hline \multicolumn{3}{|l|}{$(\mathrm{TSH})[\mu \mathrm{lU} / \mathrm{ml}]$} \\
\hline Triiodothyronine (FT3) [pmol/l] & 3.4 & $3.1-6.8$ \\
\hline Cortizol $[\mu \mathrm{g} / \mathrm{dl}]$ & 11.7 & $2.3-19.4$ \\
\hline Adrenocorticotropic hormone & 26.3 & $8.0-58.0$ \\
\hline \multicolumn{3}{|l|}{$(\mathrm{ACTH})[\mathrm{pg} / \mathrm{ml}]$} \\
\hline Hemoglobin (Hgb) [g/dl] & 9.4 & $11.0-15.0$ \\
\hline Total Cholesterol (TC) [mmol/l] & 4.1 & $3.2-5.2$ \\
\hline Sodium (Na) [mmol/l] & 138 & $136-145$ \\
\hline Echocardiography & $\begin{array}{l}\text { Ejection Fraction } \\
70 \% \text {, mitral and } \\
\text { tricuspid trace } \\
\text { regurgitation }\end{array}$ & $\begin{array}{l}\text { not } \\
\text { applicable }\end{array}$ \\
\hline $\begin{array}{l}\text { Abdomen and Adrenal } \\
\text { tomography }\end{array}$ & $\begin{array}{l}\text { No pathologies } \\
\text { within the abdomen } \\
\text { and adrenal }\end{array}$ & $\begin{array}{l}\text { not } \\
\text { applicable }\end{array}$ \\
\hline Ewing Battery tests & $\begin{array}{l}\text { No abnormalities } \\
\text { of the autonomic } \\
\text { nervous system }\end{array}$ & $\begin{array}{l}\text { not } \\
\text { applicable }\end{array}$ \\
\hline ECG and ECG stress test & Correct results & $\begin{array}{l}\text { not } \\
\text { applicable }\end{array}$ \\
\hline \multicolumn{3}{|l|}{ Consultations: } \\
\hline Neurological & \multirow{3}{*}{$\begin{array}{l}\text { No contraindications } \\
\text { to kidney transplantation. } \\
\text { No exact cause from } \\
\text { intradialytic hypotension. }\end{array}$} & \multirow{3}{*}{$\begin{array}{l}\text { not } \\
\text { applicable }\end{array}$} \\
\hline Cardiac & & \\
\hline Endocrine & & \\
\hline
\end{tabular}

additionally dobutamine infusion at a dose of 2.4$3.6 \mu \mathrm{g} / \mathrm{kg} / \mathrm{min}$ was ordered (Figs. 1 and 2). Initially, heart rate value was in range between 100 and 120 per minute, and during the reduction of aminopressor doses it decreased to normal values $(80 / \mathrm{min}$.). A delayed function of the transplanted kidney was observed, so 4 HD sessions were performed. During the post-operative period, the dosage of pressor amines was gradually reduced and stopped 18 days after transplantation. The patient was discharged from the hospital on day 22nd after transplantation in a good condition, with BP of $105 / 60 \mathrm{mmHg}$, the level of serum creatinine $117 \mu \mathrm{mol} / \mathrm{L}$ and eGFR $46 \mathrm{ml} /$ min. One year after transplantation procedure, the graft function is stable, with the level of serum creatinine of $80 \mu \mathrm{mol} / \mathrm{l}$ and eGFR $>60 \mathrm{ml} / \mathrm{min}$, BP values are approx. 105-120/60-70 mmHg (Fig. 3). The patient was well rehabilitated and returned to work.

\section{Discussion}

In the described case, before qualification for renal transplantation, we excluded causes of IDH associated with diseases of the cardiovascular system, as well as causes of endocrine and autonomic nervous system dysfunction.
Young age and lack of comorbidities also spoke in favor of the patient. Dialysis time before the kidney transplantation spanned 3 years. Undoubtedly, a factor that had an impact on the occurrence of hypotension in our patient was the performance of bilateral nephrectomy as preparation for renal transplantation. Double-sided nephrectomy or percutaneous ablation of renal sympathetic nerve are associated with a reduction in hyperactivity of the sympathetic system [5]. This has important clinical significance in patients with hypertension, particularly refractory and poorly controlled. An improvement in BP control and reduction in the number of antihypertensive medications after bilateral nephrectomy have been reported [6]. There are also reports of reduction in left ventricular mass and its diastolic dysfunction in the group of such patients [7]. In our patient, before bilateral laparoscopic nephrectomy, the $\mathrm{BP}$ values were normal. Reducing the activity of the sympathetic nervous system associated with the procedure, could therefore contribute to the onset of hypotension. In patients with chronic kidney disease (CKD) and patients on dialysis, an increased activation of the sympathetic nervous system, increased renin secretion, and increased activity of the renin-angiotensin-aldosterone system after bilateral nephrectomy were observed. Also this mechanism of BP control in our patient has been weakened. Unfortunately, due to the lack of opportunities, we did not determine in our patient the blood levels of adrenaline, noradrenaline, renin and aldosterone during the period of eligibility for transplantation.

Short-term dialysis (several months) prior to the IDH, the lack of co-morbidities, such as diabetes, autonomic neuropathy, and the correct state of the cardiovascular system (echocardiography, electrocardiography) indicate a good hemodynamic response from the myocardium and peripheral vasculature in our patient.

Rogan et al., reported the beneficial effects of exercise (stationary cycling without load during the dialysis session) on BP in a patient with IDH after bilateral nephrectomy. The exercise, performed during dialysis for 8 weeks after renal transplantation, contributed to carrying out a successful kidney transplant. The stimulation of chemoand mechanoreceptors during exercise improve BP control [8]. Our patient was also instructed as to the need to perform resistance exercises, but such exercises did not produce any major clinical effect in improving BP.

In some cases, the beneficial effect of IDH results from the use of alpha 1-adrenergic receptor agonist - midodrin. In our patient, we did not observe any beneficial effect of the use of this drug.

The correct answer to the test use of the pressor amines (dopamine) before surgery allowed for qualifying the patient for renal transplantation.

Kim et al. describe a case of kidney transplantation in a 2 -year-old child with dialysis hypotension and autonomic 


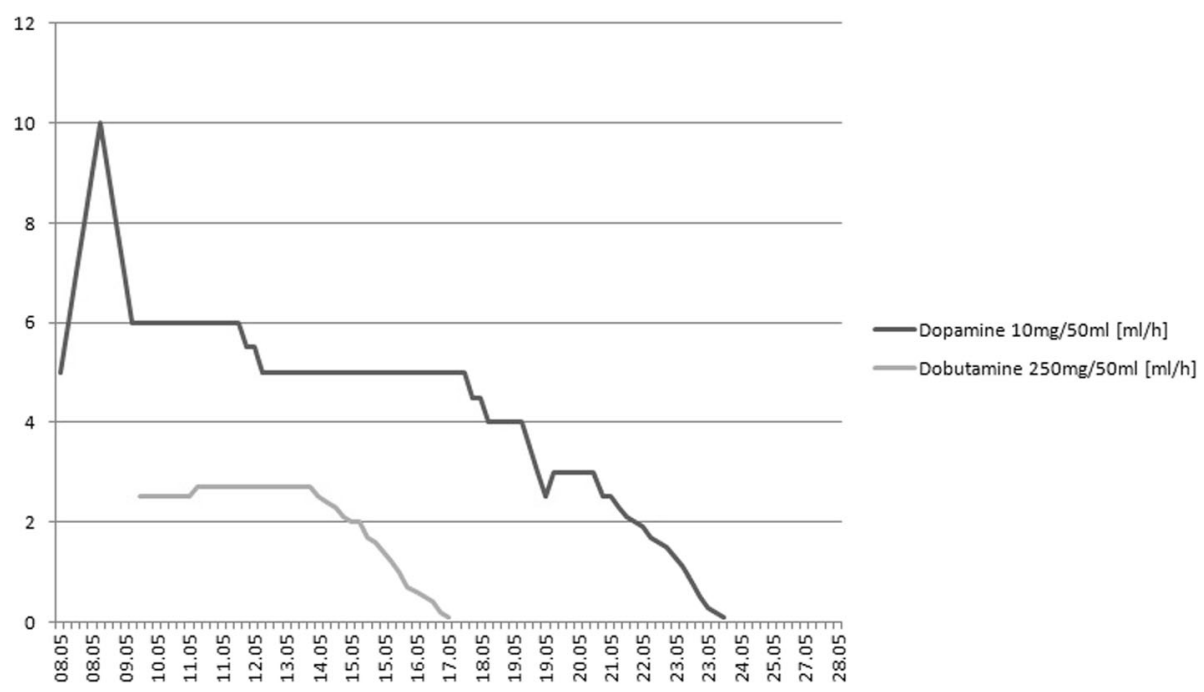

Fig. 1 Pressing amines doses during hospitalization

neuropathy, which received a transplant from an adult deceased donor. To obtain adequate perfusion of the transplanted kidney, the authors tried to achieve a value of systolic BP approx. $100 \mathrm{mmHg}$ during the perioperative period. Due to the ineffective use of dopamine infusion for this purpose, the authors successfully employed an alpha agonist (neosinefrine) for a short time, despite the risk of ischemia development and the risk of thrombosis [9]. In the case of our patient, dopamine infusions for a short period of time in conjunction with dobutamine were effective. We also observed a clear correlation between the possibility of diminishing the doses of pressor amines and improvement of the function of transplanted kidney.

A similar observation was demonstrated also by Taiwan authors [10]. They described a 59-year old hypertensive diabetic female who during 6 years on HD developed dialysis associated hypotension (in the range 80-100/50$60 \mathrm{mmHg}$ ). Blood pressure increased to the range 120 $140 / 60-80 \mathrm{mmHg}$ on day 1 st post transplantation. In other study Muscroft et al. [11] assessed the improvement of BP after a successful kidney transplantation in eight patients with IDH. They were immune high-risk patients with the presence of DSA (Donor Specific Antibodies) and had previously used the appropriate desensitizing procedures. Only one of eight patients received a kidney from a deceased donor, the others received a kidney from living donors. It should be emphasized that only four patients of this group had hypotension $<100 \mathrm{mmHg}$ between HD sessions. The authors draw attention to the large percentage of complications during the pre-transplant period (central

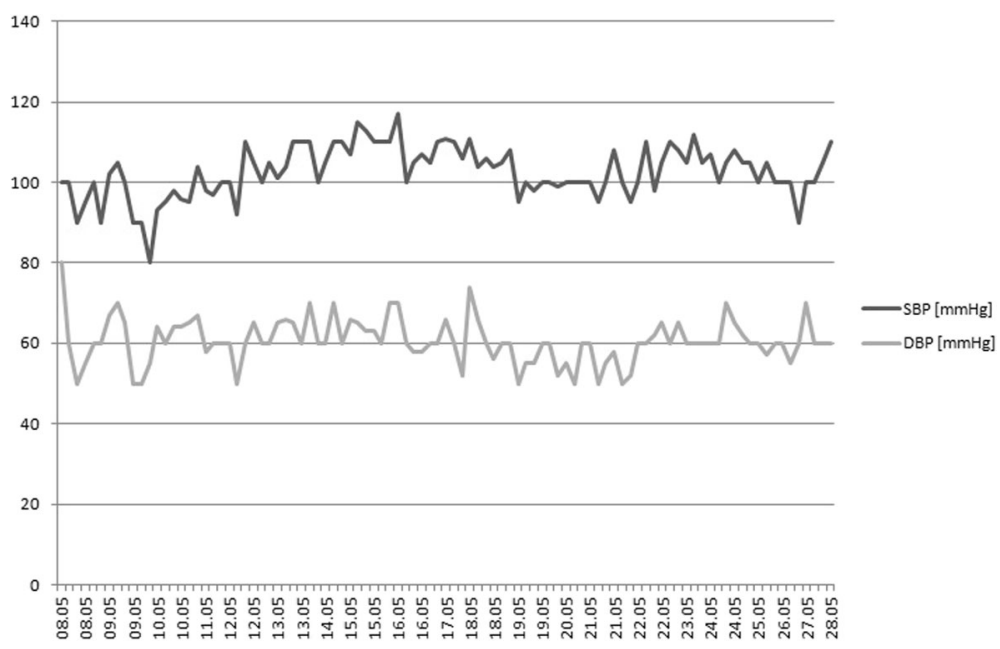

Fig. 2 Blood pressure values during hospitalization 


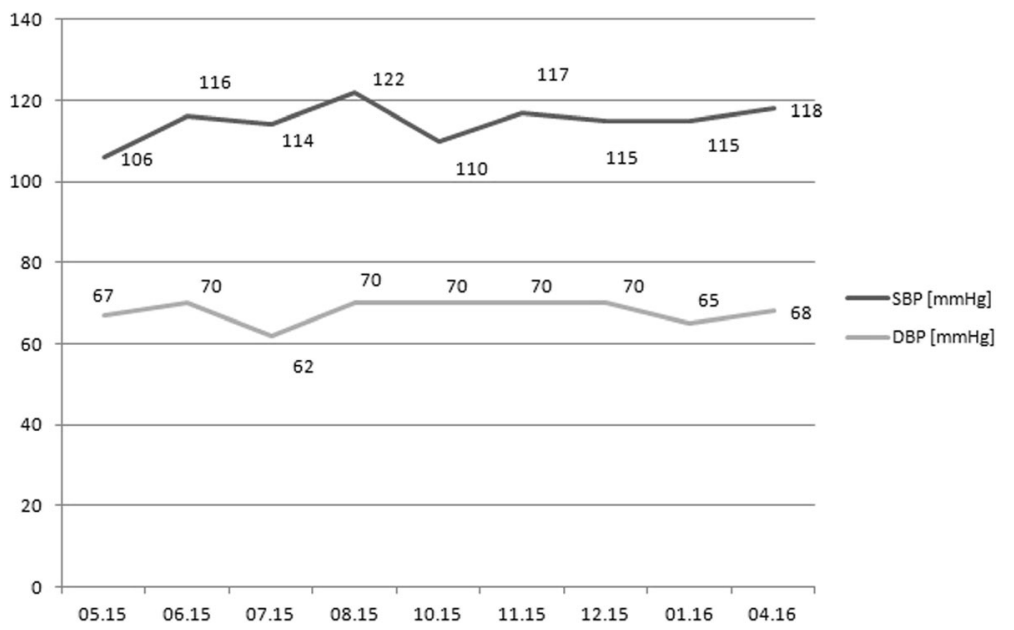

Fig. 3 Long-term post-kidney transplantation blood pressure values

retinal vein thrombosis) and the treatment period (bleeding, intestinal ischemia). One patient who received a kidney from a deceased donor died from complications associated with the occurrence of ischemic bowel disease. In these patients, different pressor amines (including norepinephrine) were used before transplantation [11]. No one of described patients with hypotension had previous bilateral nephrectomy.

\section{Conclusions}

To summarize, we for the first time described beneficial effect of kidney transplantation in severe hypotensive patients after bilateral nephrectomy. At the moment there are no adequate standards dealing with the qualifications and kidney transplantation in patients with chronic IDH. A successful kidney transplantation observed in our patient suggests careful valuation of all potential candidates for kidney transplantation, including patients with IDH. It is very important, especially for the young patients, on short-term dialysis and free of additional disease. The necessary condition, however, is the extensive diagnosis before the kidney transplantation. On the basis of this case, as a minimum, we suggest testing the cardiovascular system in accordance with the standards governing the qualifications and further endocrine studies (rhythm of cortisol, ACTH) and studies of the autonomic nervous system based on the Ewing's battery tests to exclude disorders of the autonomic nervous system. In the case of disorders of this system, it can be expected that the patient would not respond to treatment with dopamine. The use of vasoconstrictive drugs, such as phenylephrine, or high doses of norepinephrine may be associated with an increased incidence of fatal complications in this group of patients.

\section{Abbreviation}

ACTH: Adrenocorticotropic hormone; BMI: Body mass index; BP: Blood pressure; CKD: Chronic kidney disease; CT: Computed tomography; DBP: Diastolic blood pressure; DSA: Donor specific antibodies; eGFR: Estimated glomerular filtration rate; GS: Glicocorticosteroids; HD: Hemodialysis; HLA: Human leukocytes antigen; IDH: Intradialytic hypotension; KDOQI: the National Kidney Foundation's Kidney Disease Outcomes Quality Initiative; MMF: Mycophenolate-mofetil; PRA: Panel reactive antibody; SBP: Systolic blood pressure; TAC: Tacrolimus.

\section{Acknowledgements}

Not applicable.

Funding

No funding declared.

\section{Availability of data and materials}

The datasets used and/or analyzed during the current study are available from the corresponding author on reasonable request.

\section{Authors' contributions}

IE: substantial contribution to the conception and design of the work; acquisition, analysis and interpretation of data for the work; drafting the work; final approval of the version to be published; agreement to be accountable for all aspects of the work in ensuring that questions related to the accuracy or integrity of any part of the work are appropriately investigated and resolved. CD: substantial contribution to the design of the work; acquisition, analysis and interpretation of data for the work; drafting the work; final approval of the version to be published; agreement to be accountable for all aspects of the work in ensuring that questions related to the accuracy or integrity of any part of the work are appropriately investigated and resolved. BPA: substantial contribution to the analysis and interpretation of data for the work; drafting the work; final approval of the version to be published; agreement to be accountable for all aspects of the work in ensuring that questions related to the accuracy or integrity of any part of the work are appropriately investigated and resolved. OC: substantial contribution to the conception of the work; acquisition and interpretation of data for the work; critically revising the work for important intellectual content; final approval of the version to be published; agreement to be accountable for all aspects of the work in ensuring that questions related to the accuracy or integrity of any part of the work are appropriately investigated and resolved. KM: substantial contribution to the conception of the work; analysis and interpretation of data for the work; critically revising the work for important intellectual content; final approval of the version to be published; agreement to be accountable for all aspects of the work in ensuring that questions related to the accuracy or integrity of any part of the work are appropriately investigated and resolved. SW: substantial contribution to the conception and design of the work; analysis and interpretation of data for the 
work; critically revising the work for important intellectual content; final approval of the version to be published; agreement to be accountable for all aspects of the work in ensuring that questions related to the accuracy or integrity of any part of the work are appropriately investigated and resolved.

\section{Ethics approval and consent to participate}

Not applicable.

\section{Consent for publication}

The patient gave written consent for publication.

\section{Competing interests}

The authors declare that they have no competing interests.

\section{Publisher's Note}

Springer Nature remains neutral with regard to jurisdictional claims in published maps and institutional affiliations.

\section{Author details}

'Department of Nephrology, Jagiellonian University, ul. Kopernika 15C,

31-501, Krakow, Poland. 'First Department of Surgery, Jagiellonian University,

ul. Kopernika 40, 31-501, Krakow, Poland.

Received: 9 September 2016 Accepted: 12 July 2017

Published online: 20 July 2017

\section{References}

1. Rocha A, Sousa C, Teles P, Coelho A, Xavier E. Frequency of intradialytic hypotensive episodes: old problem, new insights. J Am Soc Hypertens. 2015;10:763-8

2. Sulowicz W, Radziszewski A. Pathogenesis and treatment of dialysis hypotension. Kidney Int. 2006;70:536-9.

3. Stefansson B, Brunelli S, Cabrera C, et al. Intradialytic hypotension and risk of cardiovascular disease. Clin J Am Soc Nephrol. 2014;9:2124-32.

4. Assimon M, Flythe J. Intradialytic blood pressure abnormalities: the highs, the lows and all that lies between. Am J Nephrol. 2015;42:337-50.

5. Converse R, Jacobsen $T$, Toto $R$, et al. Sympathetic overactivity in patients with chronic renal failure. N Engl J Med. 1992;327:1912-8.

6. Lerman M, Hinton S, Aronoff R. Bilateral native nephrectomy for refractory hypertenson in kidney transplant and kidney pancreas transplant patients. Int J Surg Case Rep. 2015;15:127-9.

7. Obremska M, Boratyńska M, Zyśko D, et al. Beneficial effect of bilateral native nephrectomy as complete denervation on left ventricular mass and function in renal transplant recipients. Pol Arch Med Wewn. 2016;126:58-66.

8. Rogan A, McGregor G, Weston C, et al. Exaggerated blood pressure response to dynamic exercise despite chronic refractory hypotension: results of human case study. BMC Nephrol. 2015; Jun 9;16:81. doi:10.1186/s12882-015-0076-7.

9. Kim W, Bailard N, Coveler L. The anestetic management of a child with chronic hypotension for renal transplantation. J Clin Anesthesia. 2006;18:297-9.

10. Sun C-Y, Wu M-S. Renal transplantation reversed intractable hypertension in a diabetic patients. Diabetes Care. 2007;30:e65.

11. Muscroft L, Zehnder D, Fletcher $\mathrm{S}$, et al. Rapid resolution of severe sustained low blood pressure in haemodialysis patients after successful renal transplantation. Nephrol Dial Transplant. 2012;27:4223-7.

\section{Submit your next manuscript to BioMed Central and we will help you at every step:}

- We accept pre-submission inquiries

- Our selector tool helps you to find the most relevant journal

- We provide round the clock customer support

- Convenient online submission

- Thorough peer review

- Inclusion in PubMed and all major indexing services

- Maximum visibility for your research

Submit your manuscript at www.biomedcentral.com/submit
Biomed Central 